\title{
Transformative Approaches for Sustainable Water Management in the Urban Century
}

\author{
Magnus Moglia *(1) and Stephen Cook \\ CSIRO Land and Water, Clayton 3168, Australia; stephen.cook@csiro.au \\ * Correspondence: magnus.moglia@csiro.au
}

Received: 21 May 2019; Accepted: 22 May 2019; Published: 27 May 2019

\begin{abstract}
Sustainable Urban Water Management (SUWM) approaches highlighted in this special issue have the potential to contribute to the transformation of urban water systems. The aim of the transformation is to accommodate population and economic growth and at the same time enable a system which is environmentally sustainable and resilient to future challenges such as climate change. These approaches have increasingly entered mainstream dialogue over the last ten years as knowledge on the approaches has developed, and there is an acceptance that there needs to be a change to how urban water systems are designed and operated. However, there are still a range of aspects of these approaches that are maturing and require further research to realize the objectives of SUWM. The issue explored supply-side interventions, such as rainwater harvesting and stormwater harvesting, demand-side interventions, and water storage solutions that have the potential to enable a range of recycling technologies. The issue also highlighted a novel method for better managing the integrity of a conventional sewer system. Furthermore, there are articles that explore methods for integrated assessments, integrated decision making and an exploration of what factors may promote community adoption of technology.
\end{abstract}

Keywords: sustainable urban water management; rainwater harvesting; water conservation; hybrid water supply systems; spatial planning; soil moisture investigation; managed aquifer recharge; urban flooding

\section{Introduction}

The traditional approach to providing urban water services has focused on providing drinking water for all purposes, treating wastewater and then discharging to receiving waters, and conveying stormwater rapidly away from urban areas to prevent flooding. These urban water management approaches have provided many public health and other benefits to urban populations. However, there is now an improved understanding that traditional urban water management approaches are also exacerbating urban sustainability challenges, such as inefficient use of resources and degraded ecosystems. Potential climate change impacts, such as increased flash flooding and continued rapid urban population growth that brings about disruption of ecosystems and pollution of natural water bodies [1] will compound these challenges.

As we move into the urban age [2], where most of the global population will live in cities [3], there is a need to transition to a more sustainable urban water management paradigm that can support the provision of safe and reliable water services, while contributing to more resilient and equitable cities.

Sustainable Urban Water Management (SUWM) can be defined as [4]: "an aspiration which reflects a generalized goal to manage the urban water cycle to produce more benefits than traditional approaches have delivered and therefore enhance social, ecological and economic sustainability at various scales". 
The transition is generally thought to include technologies that help manage urban runoff (i.e., stormwater harvesting, water sensitive urban design and rainwater harvesting), increased efforts to close the loop (i.e., water recycling), diversification and increased decentralization of supply sources (i.e., hybridization of water supply systems), provision of enough water for urban greening, increased water efficiency and conservation efforts, and efforts to reduce pollution loads going into waterways.

There is now a large body of literature on the topic of Sustainable Urban Water Management and similar terms. Fletcher et al. [5] undertook a thorough review of terminology associated with urban stormwater management, which highlighted that all terms are underpinned by the principles of reducing disturbance to natural hydrology and mitigating the water quality impacts of urbanization, and showed that there are subtle differences in the scope and focus of terms [5]. Often, these terms around SUWM can be viewed as a component of broader ecologically sustainable development approaches [6]. The use of terminology in the literature related to SUWM can refer to the water-sensitive management of urban stormwater [7], the increasing level of decentralization of infrastructure networks which eventually tends to turn centralized infrastructure networks into hybrid water supply systems [8], and the overall trend towards more climate adapted urban water systems that are resilient to natural disasters, drought, and other climate extremes [9-11]. In China, the term "sponge city" [12-14] is gaining traction, and also generally refers to an approach that is designed to mitigate the impacts of urbanization on waterways, particularly flooding, poor water quality and water scarcity, while concurrently adapting to projected climate change impacts [15]. There is a range of terms that are used to describe approaches designed to achieve the aspiration of SUWM. As the Swedish proverb states "a beloved child has many names". Ultimately, these terms generally refer to a broad transformational sustainability agenda for urban water management with broadly common goals.

The shared objectives across different contexts for more sustainable urban water management is not surprising. This can be viewed as a natural progression from past historical states [16], which are responding to environmental pressure and societal expectations. Nonetheless, there is some inertia in the progression towards sustainable urban water management (for simplicity, we will use this as an overarching term), which indeed has been observed [17], and this perhaps relates to issues such as:

- Sunk costs in legacy infrastructure systems, which are embedded in the socio-technical context of cities. This includes the vested interests and inherent institutional, social and cultural power structures and knowledge base that is associated with this infrastructure [4].

- Uncertainty in the implementation of new solutions, sometimes causing both under-performance as well as unintended consequences $[18,19]$. This is often not related to an inherent fault in new approaches but instead simply highlights the inherent learning processes that need to be in place so that institutional capacity can be developed [20,21].

- Macro-level drivers, such as those related to cost-effectiveness, which may be challenged by new approaches. For example, decentralized systems, a key strategy for resilience, can lead to higher costs due to reduced economies of scale, and because solutions consider more than traditional cost-benefits by including social and environmental externalities. Therefore, often only decision-making approaches that consider integrated benefits and costs will lead to solutions that are aligned with SUWM.

The transformation towards SUWM is therefore not just technological in nature. It is necessary but insufficient to identify and test the technologies that have the potential to achieve the desired goals. In fact, for widespread adoption of practices, the transformation will require the consideration of diverse stakeholder views, which can account for potential dissonance between individual goals and public goals. This calls for approaches that bring forward urban water solutions that equitably consider broader sustainability benefits across social, environmental, and economic dimensions. Transformation of complex systems, such as urban water systems, to more sustainable configurations, is often non-linear and emerges as a product of complex interdependencies. Therefore, there is a need for learning approaches that support institutions to adapt and develop appropriate governance 
arrangements. Furthermore, to support business cases for widespread adoption of SUWM, there needs to be methods and tools that illuminate the integrated impacts of technological solutions in practice, not just in theory. It is also necessary to have methods for embedding such assessments into integrated decision making and supporting holistic business models [22,23] based on a comprehensive assessment of impacts that go beyond traditional cost-benefit analysis and which embed within decision making the consideration of a broad set of societal benefits, risks and costs.

\section{Contributions}

This special issue aimed to highlight novel approaches and technologies that can accelerate the transformation of current urban water systems towards achieving the objectives embedded in SUWM. The issue explored supply-side interventions, such as rainwater harvesting and stormwater harvesting [24-26], demand-side interventions [27], and water storage solutions that have the potential to enable a range of recycling technologies [28]. The issue also highlighted a novel method for better managing the integrity of conventional sewer systems [29]. Furthermore, there are articles that explore methods for integrated assessments [30,31], integrated decision making [25,32], and an exploration of what factors may promote community adoption of a technology [26].

\subsection{Managing the Water Balance}

Efforts to improve water security in cities is part of a strategic response to develop resilience to climate change impacts and the demand pressures of rapid population growth, where the capacity of conventional water supply sources to meet demand is vulnerable. Principles for managing water supply-demand balance typically include: (1) augmentation of existing water supply sources; (2) diversification of water supply sources, such as by recycling of wastewater and/or stormwater (including rainwater) harvesting; and (3) increasing water use efficiency and/or reducing the demand for water, i.e., trying to ensure a similar or higher level of service with a reduced per capita water volume.

Hurlimann and Wilson [32] discuss the circumstances under which efforts to augment water supply could amount to maladaptation, resulting in unintended consequences, such as deterioration of public goods or increased vulnerability to extreme events. The authors note particular risks that decision makers need to be wary of, as per Table 1 . They also argue that interventions need to be put in a broader context of urban governance, with spatial planning as a way to embed climate adaptation within SUWM and to align augmentations with consideration of local ecosystems, urban heat stress, residential energy efficiency, flood control and maintaining flexibility to act under future scenarios.

Table 1. Systems-related risks of supply augmentation efforts [32].

\begin{tabular}{c}
\hline Systems-Related Risk \\
Limited social acceptability \\
Negative environmental impacts \\
Over-dependence on centralized supplies \\
Reduced incentives to adapt in the future \\
Lock-in effects reducing the future ability to act \\
One size fits all reduces the capacity for customization \\
Reduced opportunities for flood control \\
\hline
\end{tabular}

Sapkota et al. [25] explored a number of supply augmentation scenarios involving stormwater harvesting, greywater recycling, wastewater recycling and rainwater harvesting, and their impacts on a range of technical parameters which has a direct impact on costs, service quality and environmental outcomes, as shown in Table 2. The various trade-offs between different solutions are highlighted, with different augmentation options preferred depending on which of these metrics are considered most important. With the priorities adopted by local stakeholders, the option of a centralized water supply system along with stormwater harvesting was found to be the best option, and the worst option 
was a centralized system along with treated wastewater. However, the authors demonstrate, based on sensitivity analysis, how the local context and priorities may dictate the preference for different augmentation options. Importantly, the conclusion from this paper is that SUWM does not necessarily involve a wholesale departure from centralized water systems, but urban communities are likely to be much better served by hybrid water supply systems that concurrently draw key benefits from both centralized and decentralized infrastructure systems. The result is what is referred to as hybrid water supply systems [8].

Table 2. Technical performance metrics for supply augmentation efforts [25].

\begin{tabular}{c} 
Technical Performance Metrics \\
\hline Reduction in potable water demand from the centralized system \\
Reduction of wastewater generation \\
Reduction of contaminant concentrations in wastewater \\
Reduction in stormwater flows \\
Reduction in contaminant (TSS, TP, TN, BOD, and COD) load in stormwater \\
Increased supply reliability of fit-for-purpose water under a range of scenarios \\
\hline
\end{tabular}

In evaluating a particular supply augmentation in Washington D.C. against similar metrics as those used by Sapkota et al. [25], Braga and colleagues [24] evaluate an advanced rainwater harvesting system implementation, focusing on the engineering and operational aspects of the systems, and in doing so identify another array of performance metrics for supply augmentations, as per Table 3. Based on the monitored performance and assessment of the operational performance metrics, the authors provide a strong endorsement of the advanced rainwater harvesting system as a viable low impact development option.

Table 3. Operational performance metrics for supply augmentation efforts [24].

\begin{tabular}{c}
\hline Operational Performance Metrics \\
\hline Design and construction cost \\
Area needed \\
Operation and maintenance requirements \\
\hline
\end{tabular}

Furthermore, as noted by Hurlimann and Wilson [32], demand-side interventions, whilst often highly effective, are often under-utilized because of difficulties in predicting the performance of efforts. In line with this argument, Moglia et al. [27] explore how the science of water conservation can be developed to provide more accurate predictions and provide decision makers with greater confidence in choosing demand-side interventions. To address this issue, they argue for the need for more longitudinal studies into the effectiveness of water conservation efforts, further research into how different communication styles impact results, and to raise the behavioral science capability in support of water conservation efforts.

\subsection{Storage, Distribution and Collection}

There are novel approaches to water treatment and storage that can support the achievement of SUWM objectives. One of these approaches is the storage of water in groundwater aquifers. Page et al. [28] propose that managed aquifer recharge (MAR) technologies "not only act as a water supply and treatment technology but as an integral part of green infrastructure in sustainable urban water management". MAR, when well-designed and managed, can enable effective treatment of stormwater and wastewater for recycled water systems. However, as a natural treatment system, there is a need for site-specific investigations to understand likely water quality improvements, such as a reduction in pathogens, and organic and inorganic pollutants. MAR can also provide a useful approach for water storage that counters issues with surface water storage, including evaporative 
losses. Page and colleagues [28] however also note that more knowledge is required to allow MAR to be better integrated into SUWM, which includes understanding how triple-bottom-line assessment can be embedded into decision-making processes which evaluate MAR in relation to coastal water quality impacts, greenhouse gas emissions, aquifer restoration and urban amenity. There is also a need to increase the capacity for managing MAR schemes, which can be technically challenging and often have diseconomies of scale.

SUWM objectives will often be achieved with hybrid wastewater systems that combine conventional, centralized systems with decentralized systems that include novel approaches, such as water recycling. Beheshti and Saegrov [29] explore how to limit the infiltration and inflow of unwanted water into the sewer system which can often equate to nearly half of the wastewater volume in sewer networks. This is associated with diminished treatment performance and increased costs, an increase in the risk of local flooding and sanitary sewer overflow in urban areas, as well as a considerable increase in pumping energy. Efforts to improve the performance of wastewater systems is critically important, and recent advances such as the use of fiber-optic distributed temperature sensing [29] show promising results in helping infrastructure operators to improve sustainability and reduce costs.

\subsection{Monitoring, Measuring and Assessing Outcomes}

The purpose of SUWM is to achieve outcomes beyond simply providing the appropriate level of water services at the lowest price. But what should SUWM achieve, and how will we monitor and measure outcomes? These are critically important questions for SUWM, and there is a need to:

- Decide on key performance indicators

- Set up monitoring frameworks

- Define frameworks for assessing the likely outcomes of interventions on outcomes

- Embed new indicators and frameworks into decision making

One of the key issues to embed into decision making relates to urban flooding and associated damage. In fact, Lee and Kim [30] propose a flooding resilience index based on multi-dimensional flood damage analysis which allows for ongoing monitoring of flooding risk. It can be used to evaluate the impact of infrastructure-related decisions on flood risk, and could, therefore, be part of a SUWM-based adaptive governance framework.

Another important performance metric relating to SUWM relates to the level of urban greening in a city. Adequate soil moisture levels are needed to support healthy vegetation as part of a green infrastructure approach, which provides important benefits to local ecosystems and human health. An emerging area of research is the use of remote sensing to monitor green infrastructure performance. In an exciting paper on this topic, Qu et al. [31] illustrate how the use of remote sensing combined with machine learning based on sampled soil moisture can support ongoing monitoring of soil moisture in Beijing. Landsat5-TM images were used for monitoring, which provide a relatively accessible data source. The use of remote sensing for monitoring performance is an important addition to the SUWM toolbox.

Sapkota and colleagues [25] also provide a useful example of how Multi-Criteria Assessment (MCA) can support decision-makers in evaluating SUWM approaches. The complexity of evaluating possible SUWM approaches across a diverse range of performance indicators can be supported by MCA that provides a transparent approach for making trade-offs. Another approach could be to set target thresholds as part of goal setting, and assessing the likelihood of jointly achieving those goals [33].

\subsection{Social Acceptance}

Technological approaches for SUWM require acceptance across the broader community to ensure successful adoption. A lack of social acceptance can thwart the adoption of SUWM approaches [34] such as the case in Toowoomba where a proposed water recycling scheme was not realized due to 
strong public opposition, despite water storages being at critically low levels, and experts' opinions that indicated the recycled water scheme would be safe [34]. Rainwater harvesting systems have also been evaluated based on expected benefits and costs [35-37]. In this special issue, there is an exploration of the rainwater tank features that will increase community adoption rates [26]. This paper found that rainwater tank features (e.g., slimline tanks) that ensure integration with building design are attractive to households and that people are generally willing to pay for a larger tank. The adoption of more sustainable behaviors and technologies are often slow to gather traction across a population, which highlights the need for more nuanced efforts in targeting incentives for the increased uptake of sustainable technologies [38,39].

\section{Discussion}

Over recent decades, there has been a growing recognition that most developed cities around the world need to transition to more sustainable configurations of urban water systems that ensure essential services, such as clean water supply and adequate sanitation, are maintained while contributing to ecologically sustainable development that conserves natural resources for future generations [40].

There is the need to urgently address unsustainable aspects of urban water systems, such as over-utilization of freshwater resources and pollution of receiving waters, which will be compounded by growing urban populations and climate change impacts. Harding [40] highlighted that in cities, where despite high levels of water conservation and uptake of water recycling schemes, there are projected water shortages unless per capita demand is reduced, or supply is augmented. At a regional level, Ferguson [41] demonstrates a common and already water constrained situation where there is an expectation that water demand will need to grow by an order of magnitude in order to accommodate population and economic growth. It is often very difficult to see how this can be achieved without significant advances in water efficiency and high levels of water recycling.

SUWM approaches highlighted in this special issue have the potential to contribute to the transformation of urban water systems to accommodate population and economic growth and at the same time enable a system which is environmentally sustainable, and also resilient to future challenges such as climate change.

SUWM approaches have increasingly entered mainstream dialogue over the last ten years as knowledge on the approaches has developed, and there is an acceptance that there needs to be a change to how urban water systems are designed and operated. However, there are still a range of SUWM aspects that are maturing, and require further research, to realize the objectives of SUWM. The special issue and this editorial have highlighted several areas that require further investigation.

The first topic that needs further investigation is to better understand how novel, decentralized approaches can be planned and implemented to complement conventional, centralized urban water systems. These hybrid systems are likely to be strengthened by the diversity of approaches and technologies, but there are still challenges to be addressed, such as how to best provide adequate operation and maintenance to more complex systems with distributed, small-scale assets across a city.

The second topic that needs further investigation is to explore how the use of natural processes, such as MAR, can provide effective water treatment. There is a need to better understand the expected performance and feasibility in a range of contexts as the design will have to reflect the variability in local climate, soils, geology, etc.

The third topic that needs further investigation is to research improved approaches to embed SUWM in the wider governance of cities that considers the interdependencies of urban water systems across sectors and levels of government. This includes the development of robust and consistent performance metrics that can be used to monitor and evaluate the achievement of SUWM policy objectives. This includes understanding how approaches such as MCA can be used to inform the evaluation of acceptable trade-offs in performance across triple-bottom-line outcomes. 
The final topic that requires further investigation is on the human behavioral factors that influence social acceptance of SUWM approaches, and how incentives can be structured to trigger greater uptake across the community.

Author Contributions: Conceptualization, M.M. and S.C.; methodology, M.M. and S.C.; writing-original draft preparation, M.M.; writing - review and editing, M.M. and S.C.

Funding: This research received no external funding.

Acknowledgments: We acknowledge the constructive reviews by our colleagues Tim Muster and Sorada Tapsuwan.

Conflicts of Interest: The authors declare no conflict of interest.

\section{References}

1. Debo, T.; Reese, A. Municipal Stormwater Management, 2nd ed.; CRC Press: Boca Raton, FL, USA, 2002.

2. Gleeson, B. Critical commentary. The urban age: Paradox and prospect. Urban Stud. 2012, 49, 931-943.

3. Mishra, V.; Ganguly, A.R.; Nijssen, B.; Lettenmaier, D.P. Changes in observed climate extremes in global urban areas. Environ. Res. Lett. 2015, 10, 024005. [CrossRef]

4. Marlow, D.R.; Moglia, M.; Cook, S.; Beale, J. Towards Sustainable Urban Water Management: A Critical Reassessment. Water Res. 2013, 47, 7150-7161. [CrossRef]

5. Fletcher, T.D.; Shuster, W.; Hunt, W.F.; Ashley, R.; Butler, D.; Arthur, S.; Trowsdale, S.; Barraud, S.; Semadeni-Davies, A.; Bertrand-Krajewski, J.-L.; et al. SUDS, LID, BMPs, WSUD and more-The evolution and application of terminology surrounding urban drainage. Urban Water J. 2015, 12, 525-542. [CrossRef]

6. Wong, T.H.F. Water sensitive urban design—The journey thus far. Australas. J. Water Resour. 2006, 10, 213-222. [CrossRef]

7. Ferguson, B.C.; Brown, R.R.; Deletic, A. Diagnosing transformative change in urban water systems: Theories and frameworks. Glob. Environ. Chang. 2013, 23, 264-280. [CrossRef]

8. Sapkota, M.; Arora, M.; Malano, H.; Moglia, M.; Sharma, A.; George, B.; Pamminger, F. An overview of hybrid water supply systems in the context of urban water management: Challenges and opportunities. Water 2015, 7, 153-174. [CrossRef]

9. Hoekstra, A.Y.; Buurman, J.; Van Ginkel, K.C.H. Urban water security: A review. Environ. Res. Lett. 2018, 13, 053002. [CrossRef]

10. Blackmore, J.M.; Plant, R.A.J. Risk and resilience to enhance sustainability with application to urban water systems. J. Water Resour. Plan. Manag. 2008, 134, 224-233. [CrossRef]

11. Leigh, N.G.; Lee, H. Sustainable and resilient urban water systems: The role of decentralization and planning. Sustainability 2019, 11, 918. [CrossRef]

12. Van Rooijen, D.J.; Turral, H.; Biggs, T.W. Sponge city: Water balance of mega-city water use and wastewater use in Hyderabad, India. Irrig. Drain. 2005, 54, S81-S91. [CrossRef]

13. Li, H.; Ding, L.; Ren, M.; Li, C.; Wang, H. Sponge city construction in China: A survey of the challenges and opportunities. Water 2017, 9, 594. [CrossRef]

14. Li, X.; Li, J.; Fang, X.; Gong, Y.; Wang, W. Case Studies of the Sponge City Program in China. In Proceedings of the World Environmental and Water Resources Congress 2016: Watershed Management, Irrigation and Drainage, and Water Resources Planning and Management, West Palm Beach, FL, USA, 22-26 May 2016; pp. 295-308.

15. Wang, H.; Cheng, X.; Man, L.; Li, N. Challenges and Future Improvemnets to China's Sponge City Construction. In Proceedings of the International Low Impact Development Conference China 2016: LID Applications in Sponge City Projects, Beijing, China, 26-29 June 2016; pp. 339-351.

16. Brown, R.R.; Keath, N.; Wong, T.H.F. Urban water management in cities: historical, current and future regimes. Water Sci. Technol. 2009, 59, 847-855. [CrossRef] [PubMed]

17. Wong, T.; Brown, R. Transitioning to Water Sensitive Cities: Ensuring Resilience through a new Hydro-Social Contract. In Proceedings of the 11th International Conference on Urban Drainage, Edinburgh, UK, 31 August-5 September 2008; p. 10.

18. Moglia, M.; Gan, K.; Delbridge, N. Exploring methods to minimize the risk of mosquitoes in rainwater harvesting systems. J. Hydrol. 2016, 543, 324-329. [CrossRef] 
19. Moglia, M.; Gan, K.; Delbridge, N.; Sharma, A.K.; Tjandraatmadja, G. Investigation of pump and pump switch failures in rainwater harvesting systems. J. Hydrol. 2016, 538, 208-215. [CrossRef]

20. Bos, J.J.; Brown, R.R.; Farrelly, M.A.; de Haan, F.J. Governance experimentation: A descriptive analysis of translating sustainable urban water management in practice. In WSUD 2012: Water Sensitive Urban Design; Building the Water Sensitive Community; 7th International Conference on Water Sensitive Urban Design; Engineers Australia: Barton, Australia, 2012; pp. 865-872.

21. Bos, J.J.; Brown, R.R.; Farrelly, M.A.; de Haan, F.J. Enabling sustainable urban water management through governance experimentation. Water Sci. Technol. 2013, 67, 1708-1717. [CrossRef]

22. Marlow, D.R.; Müller, N.A.; Moglia, M. The role of business models and transitional pressures in attaining sustainable urban water management. Urban Water J. 2017, 14, 868-875. [CrossRef]

23. Müller, N.A.; Marlow, D.R.; Moglia, M. Business model in the context of Sustainable Urban Water Management-A comparative assessment between two urban regions in Australia and Germany. Util. Policy 2016, 41, 148-159. [CrossRef]

24. Braga, A.; O'Grady, H.; Dabak, T.; Lane, C. Performance of two advanced rainwater harvesting systems in Washington DC. Water 2018, 10, 667. [CrossRef]

25. Sapkota, M.; Arora, M.; Malano, H.; Sharma, A.; Moglia, M. Integrated evaluation of hybridwater supply systems using a PROMETHEE-GAIA approach. Water 2018, 10, 610. [CrossRef]

26. Tapsuwan, S.; Cook, S.; Moglia, M. Willingness to pay for rainwater tank features: A post-drought analysis of Sydney water users. Water 2018, 10, 1199. [CrossRef]

27. Moglia, M.; Cook, S.; Tapsuwan, S. Promoting water conservation: Where to from here? Water 2018, 10, 1510. [CrossRef]

28. Page, D.; Bekele, E.; Vanderzalm, J.; Sidhu, J. Managed aquifer recharge (MAR) in sustainable urban water management. Water 2018, 10, 239. [CrossRef]

29. Beheshti, M.; Sægrov, S. Quantification assessment of extraneous water infiltration and inflow by analysis of the thermal behavior of the sewer network. Water 2018, 10, 1070. [CrossRef]

30. Lee, E.H.; Kim, J.H. Development of resilience index based on flooding damage in urban areas. Water 2017, 9, 428. [CrossRef]

31. Qu, Y.; Qian, X.; Song, H.; Xing, Y.; Li, Z.; Tan, J. Soil moisture investigation utilizing machine learning approach based experimental data and Landsat5-TM images: A case study in the Mega City Beijing. Water 2018, 10, 423. [CrossRef]

32. Hurlimann, A.; Wilson, E. Sustainable urban water management under a changing climate: The role of spatial planning. Water 2018, 10, 546. [CrossRef]

33. Moglia, M.; Perez, P.; Burn, S. Assessing the likelihood of realizing idealized goals: the case of urban water strategies. Environ. Model. Softw. 2012, 35, 50-60. [CrossRef]

34. Hurlimann, A.; Dolnicar, S. When Public Opposition Defeats Alternative Water Projects-The Case of Toowoomba Australia. Water Res. 2010, 44, 287-297. [CrossRef]

35. Castonguay, A.C.; Urich, C.; Iftekhar, M.S.; Deletic, A. Modelling urban water management transitions: A case of rainwater harvesting. Environ. Model. Softw. 2018, 105, 270-285. [CrossRef]

36. Fuentes-Galván, M.L.; Ortiz Medel, J.; Arias Hernández, L. Roof rainwater harvesting in central Mexico: Uses, benefits, and factors of adoption. Water 2018, 10, 116. [CrossRef]

37. Kandiah, V.K.; Zechman, E.M. Agent-based modeling for simulating the decentralization of urban water infrastructure systems. In Proceedings of the World Environmental and Water Resources Congress 2012: Crossing Boundaries, Albuquerque, NM, USA, 20-24 May 2012.

38. Moglia, M.; Cook, S.; McGregor, J. A review of Agent-Based Modelling of Technology Diffusion with special reference to residential energy efficiency. Sustain. Cities Soc. 2017, 31, 173-182. [CrossRef]

39. Moglia, M.; Podkalicka, A.; McGregor, J. An agent-based model of residential energy efficiency adoption. J. Artif. Soc. Soc. Simul. 2018, 21,1-26. [CrossRef] 
40. Harding, R. Ecologically sustainable development: origins, implementation and challenges. Desalination 2006, 187, 229-239. [CrossRef]

41. Ferguson, D. Modelling Western Australia's Water Demand and Supplies. In Proceedings of the OzWater'19, Melbourne, Australia, 7-9 May 2019.

(C) 2019 by the authors. Licensee MDPI, Basel, Switzerland. This article is an open access article distributed under the terms and conditions of the Creative Commons Attribution (CC BY) license (http://creativecommons.org/licenses/by/4.0/). 